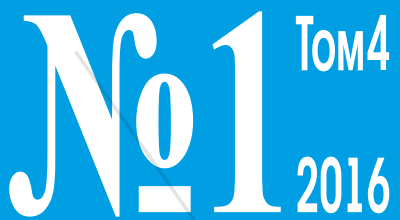

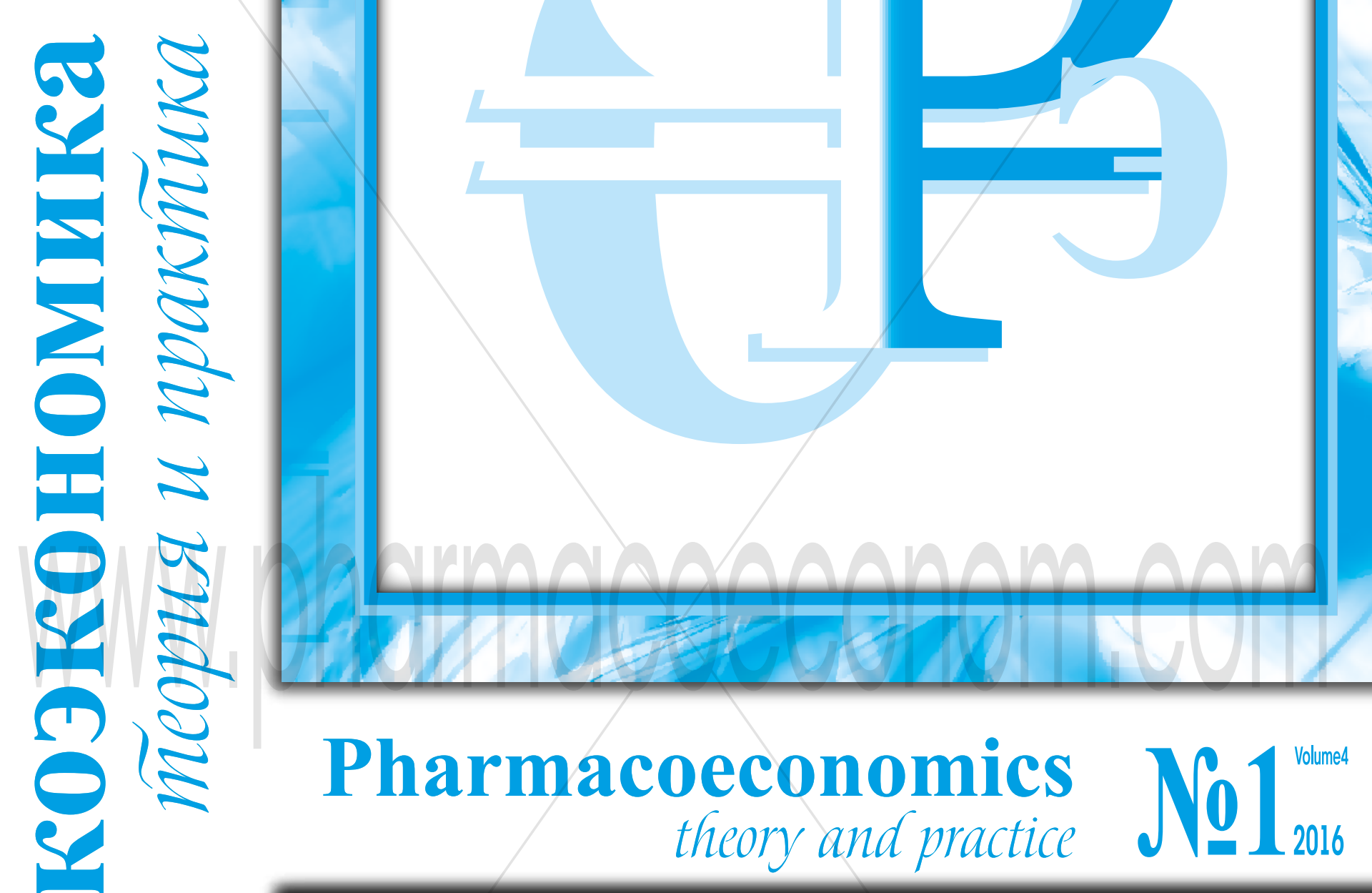

$\square$ МЕТОДОЛОГИЧЕСКИЕ ОСНОВЫ ФАРМАКОЭКОНОМИЧЕСКОГО МОДЕЛИРОВАНИЯ

$\square$ РЕЗУЛЬТАТЫ РОССИЙСКИХ ФАРМАКОЭКОНОМИЧЕСКИХ ИССЛЕДОВАНИЙ

口 МАТЕРИАЛЫ Х НАЦИОНАЛЬНОГО КОНГРЕССА С МЕЖДУНАРОДНЫМ УЧАСТИЕМ «РАЗВИТИЕ ФАРМАКОЭКОНОМИКИ И ФАРМАКОЭПИДЕМИОЛОГИИ В РОССИЙСКОЙ ФЕДЕРАЦИИ» 4-5 апреля 2016 г., г. Нижний Новгород 


\section{ФАРМАКОЭКОНОМИЧЕСКИЙ АНАЛИЗ ЛЕКАРСТВЕННОГО СРЕДСТВА ВЕЛЬФОРО 500 (КОМПЛЕКС В-ЖЕЛЕЗА (III) ОКСИГИДРОКСИДА, САХАРОЗЫ И КРАХМАЛА) В ЛЕЧЕНИИ ГИПЕРФОСФАТЕМИИ У ПАЦИЕНТОВ С ХРОНИЧЕСКОЙ БОЛЕЗНЬЮ ПОЧЕК}

Угрехелидзе Д.Т., Куликов А.Ю.

ГБОУ ВПО «Первый МГМУ им. И.М. Сеченова»

\section{Резюме:}

В рамках данной работы было проведено фармакоэкономическое исследование терапии гиперфосфотемии фосффат-связывающими препаратами у пациентов с хронической болезнью почек (ХБП). Сравнивались шесть схем терапии: комплекс $\beta$-железа (III) оксигидроксида, сахарозы и крахмала (Вельфоро $\left.{ }^{\circledR} 500\right)$, севеламера карбонат, севеламера гидрохлорид, кальция ацетат, кальция карбонат, кальция ацетат+магния карбонат. По результатам проведенного анализа «затраты-эфрфективность» при терапии гиперфосфратемии было установлено, что коэфффициенты «затраты-эффективность" в сравниваемых схемах терапии с использованием в качестве критерия эффрективности общей годичной выживаемости были равны следующим значениям для препаратов: Вельсооро ${ }^{\circledR} 500$ 1663679 руб., севеламера карбонат - 1723277 руб., севела мера гидрохлорид - 1723299 руб., кальция карбонат - 2381086 руб., кальция ацетат -2286 086 руб., кальция ацетат+магния карбонат -2 416638 руб. При использовании в качестве критерия эфффективности снижение уровня фосфора в сыворотке крови на конец первого года терапии было установлено, что коэфффициенты «затраты-эфффективность» равны следующим значениям для сравниваемых препаратов: Вельфоро ${ }^{\circledR} 500$ - 2062024 руб., севеламера карбонат - 2297702 руб., севеламера гидрохлорид 2297733 руб., кальция карбонат- 2709861 руб., кальция ацетат 2601408 руб., кальция ацетат+магния карбонат -2 899965 руб. С точки зрения анализа «влияния на бюджет» на конец 1 года при расчетах на 1 пациента наименее затратной схемой оказалась терапия Вельфроро ${ }^{\circledR} 500(1$ 464037 руб.). Затраты в группе севеламера гидрохлорида составили 1516 504 руб., в группе севеламера карбоната - 1516483 руб., в группе кальция карбоната составила 1571719 руб., кальция ацетат - 1508816 руб., кальция ацетат+магния карбонат - 1594981 руб.

Таким образом, результаты фрармакоэкономического анализа показывают, что терапия гиперфоссратемии у пациентов с хронической болезнью почек с применением Вельфроро ${ }^{\circledR} 500$ предпочтительна по сравнению с другими фоссфат-связывающими препаратами, так как одновременно с сокращением общих затрат позволяет значительно снизить уровень фосфора в сыворотке крови, обеспечивает снижение числа осложнений и лучшую выживаемость при меньшей лекарственной нагрузке по сравнению с другими как с кальцийсодержащими, так и с не содержащими кальций фосфат-связывающими препаратами.

Ключевые слова: анализ эффрективности, анализ затрат, анализ «затраты-эфффективность», анализ «влияния на бюджет», гиперфосфатемия, комплекс $\beta$-железа (III) оксигидроксида, сахарозы и крахмала, севеламера карбонат, севеламера гидрохлорид, кальция ацетат, кальция карбонат, кальция ацетат + магния карбонат, фармакоэкономика, клинико-экономический анализ.

\section{Введение}

Нарушения минерального и костного обмена или минерально-костные нарушения (МKH) - широко распространенные осложнения хронической болезни почек (ХБП). Эта патология значительно ухудшает прогноз и встречается практически у всех больных в терминальной стадии ХБП, а начальные проявления минеральных нарушений в виде внутриклеточного накопления фоссратов, компенсаторного повышения уровня FGF-23 и снижения активности альфа-гидроксилазы появляются уже на ранних стадиях ХБП [1]. Результаты многочисленных эпидемиологических, экспериментальных и клинических исследований показали, что системные нарушения минерально-костного обмена при ХБП (ХБП-МКН) тесно связаны с кардиоваскулярной патологией (кардиоренальный синдром), поражением костной ткани и сосудов [2]. По данным международного исследования, проводившегося в 2005 году в репрезентативных выборках диализных пациентов в 7 странах (Франции, Германии, Италии, Японии, Испании, Великобритании и США), распространенность гиперфоссратемии составила 49,4\% в странах Европы и 53,6\% в Японии [3].

Основанием для контроля сывороточного уровня фоссратов у больных ХБП служат результаты эпидемиологических исследований, свидетельствующие о том, что гиперфоссратемия повышает риск смерти от любых и сердечно-сосудистых причин и способствует развитию эктопической кальцификации сосудов, клапанов и мягких тканей [3]. Недавно в исследовании DOPPS было показано, что связь между повышением сывороточных уровней фросфора и относительным риском смерти от любых причин сопоставима в различных странах. В большинстве исследований наблюдали увеличение риска смерти начиная с уровня фосфрора, превышающем 1,6-1,8 ммоль/л. Эпидемиологические данные подтверждаются результатами экспериментальных исследований, свидетельствующими о наличии прямой причинно-следственной связи между повышенными уровнями фоссратов и другими проявлениями МКН-ХБП, в том числе вторичным гиперпаратиреозом, поражением костной ткани, недостаточностью кальцитриола и эктопической кальцификацией [3].

В национальных рекомендациях по МКН-ХБП [1] у пациентов с ХБП 3-5 стадии рекомендовано поддерживать уровень фоссратов сыворотки крови в нормальном диапазоне (с поправкой на нормы локальной лаборатории), а у больных на диализе - стремиться к снижению уровня фосфатов крови до нормальных значений. Доля пациентов с уровнем фоссратов ниже 1,9 ммоль/л в диализном центре должна составлять не менее $70 \%$. Для контроля гиперфосфратемии у больных ХБП используют диету и фоссрат-связывающие препараты (ФСП), а также увеличение длительности диализа [3].

Коррекция нарушений фросфорно-кальциевого обмена представляет собой обязательный компонент долгосрочной стратегии ведения пациентов, страдающих хронической болезнью почек как на более ранних, 
так и, тем более, на последующих IV—V стадиях. Контроль за степенью кальцификации аорты и ее висцеральных ветвей, в частности коронарных артерий, принципиально важен с точки зрения уменьшения риска сердечно-сосудистых осложнений - лидирующей причины смерти пациентов с хронической почечной недостаточностью. С этой точки зрения ФСП могут по праву претендовать на роль одной из важнейших терапевтических стратегий, значение своевременного начала применения которой и рационального выбора конкретного препарата трудно переоценить в плане управления долгосрочным прогнозом пациента с хронической болезнью почек. [3]

Учитывая социальную значимость и значительное бремя хронической болезни почек и нарушений минерального и костного обмена при ХБП для здравоохранения Российской Федерации представляется актуальным проведение фармакоэкономического анализа терапии гиперфоссратемии у пациентов с хронической болезнью почек. Актуальность данной работы заключается в том, что авторами впервые описаны фармакоэкономические последствия внедрения нового ФСП Вельфоро ${ }^{\circledR 500}$ (комплекса $\beta$-железа (III) оксигидроксида, сахарозы и крахмала) в систему здравоохранения Россйиской Федерации в сравнении с другими содержащими- и не содержащими кальций ФСП.

Говоря о международном опыте клинико-экономического анализа препарата Вельфоро ${ }^{\circledR 500}$ следует отметить работу немецкого ученого Florian S. Gutzwiller и коллег, в которой сравнивали фрармакоэкономические последствия терапии препаратами комплекса $\beta$-железа (III) оксигидроксида, сахарозы и крахмала и севеламера карбоната в условиях системы здравоохранения Шотландии. Авторами было показано, что за счет снижения лекарственной нагрузки и более низкой стоимости суточной дозы лечение препаратом комплекса $\beta$-железа (III) оксигидроксида ,сахарозы и крахмала по сравнению с севеламера карбонатом у пациентов ХБП с гиперфоссратемией, которым противопоказаны ФСП на основе кальция, является экономически более эффективным с точки зрения шотландской Национальной службы здравоохранения [31]

Цель исследования - определить наиболее предпочтительное с точки зрения фрармакоэкономического анализа лекарственное средство, используемое при лечении гиперфоссратемии у пациентов с хронической болезнью почек на основании анализа «влияния на бюджет» и сравнения соотношения между затратами и эфффективностью.

Для достижения поставленной цели последовательно решались следующие задачи:

1. Сбор и анализ данных клинической практики использования ФСП (комплекс $\beta$-железа (III) оксигидроксида, сахарозы и крахмала, севеламера карбонат, севеламера гидрохлорид, кальция ацетат, кальция карбонат, кальция ацетат + магния карбонат) в лечении гиперфоссратемии у пациентов ХБП.

2. Выбор критериев эфффективности применения ФСП в лечении гиперфоссратемии у пациентов ХБП.

3. Анализ затрат при использовании сравниваемых схем лечения гиперфоссфатемии у пациентов ХБП.

4. Проведение следующих методов в рамках фрармакоэкономического исследования: анализ «затраты-эфффективность», анализ «влияния на бюджет», анализ чувствительности.

В результате данного фармакоэкономического исследования была построена аналитическая модель в формате Microsoft Excel 2013, позволяющая проводить как на федеральном, так и на региональном уровне компьютерное моделирование клинико-экономических последствий принятых решений в области выбора лекарственных средств для лечения гиперфоссратемии у больных ХБП с помощью современных методов фрармакоэкономического анализа.

\section{Объекты исследования:}

1. Комплекс $\beta$-железа (III) оксигидроксида, сахарозы и крахмала (Вельфоро $0^{\circledR 500)}$

2. Севеламер карбонат (Селамерекс $\left.{ }^{\circledR}\right)$

3. Севеламер гидрохлорид (Ренагель $\left.{ }^{\circledR}\right)$

4. Кальция карбонат (Аддитива кальций)

5. Кальция ацетат (Нефродин)

6. Кальция ацетат + магния карбонат $\left(0 \mathrm{cваРен}{ }^{\circledR}\right)$

\section{Анализ эффективности}

На первом этапе данного исследования был проведен информационный поиск с использованием данных крупнейших библиографических баз: Medline, Medscape, PubMed, Cochrane Library, в базе данных «Российская медицина» Центральной научной медицинской библиотеки Первый МГМУ имени И.М. Сеченова, научной электронной библиотеки elibrary. ru, свободных поисковых ресурсах таких как Yandex, Google. Поисковый запрос включал термины: «гиперфоссратемия», «комплекс $\beta$-железа (III) оксигидроксида, сахарозы и крахмала», «севеламер», «ацетат кальция», «карбонат кальция», «хроническая болезнь почек», «фрармакоэкономика гиперфоссратемии», «выживаемость при гиперфоссратемии», «снижение уровня фосфора в сыворотке крови", а также переводы данных терминов на английском языке. Был проведен поиск сравнительных исследований эфффективности для всех ФСП, зарегистрированных в РФ на данный момент.

В ходе информационного поиска было найдено два рандомизированных клинических исследования:

- Floege J, Covic AC, Ketteler M, Rastogi A, Chong EM, Gaillard S, et al. A phase III study of the efficacy and safety of a novel iron-based phosphate binder in dialysis patients. [9]

- Floege J, Covic AC, Ketteler M, Mann JFE, Rastogi A, Spinowitz B, et al. Long-term effects of iron-based phosphate binder,sucroferric oxyhydroxide, in dialysis patients. [10]

Следует отметить, что данные исследования включают одну и ту же популяцию больных, различия заключались лишь в длительности временного горизонта. Эти работы являются единственными опубликованными рандомизированными клиническими исследованиями, в которых статистически обоснованно и с высокой степенью достоверности результатов была сопоставлена эфффективность Вельфоро ${ }^{\circledR} 500$ и севеламера карбоната.

Для сравнения эффективности севеламера карбоната и солей кальция (кальция ацетата и кальция карбоната) были использованы данные мета-анализа Jamal S.A. [11] В данном исследовании были учтены данные о 4622 пациентах из 11 рандомизированных клинических исследований.

Для оценки эффективности препаратов кальция ацетата+магния карбоната было использовано обсервационное исследование Ángel L.M. de Francisco [12], основанное на данных реальной клинической практики. Были собраны данные об эфффективности терапии 120 пациентов, получавших препарат кальция+магния карбоната в течение 12 месяцев.

На основании проведенного информационного поиска были определены критерии эфффективности, позволяющие провести фармакоэкономическую оценку применения сравниваемых технологий здравоохранения в профилактике гиперфоссратемии. В данном исследовании ими являются:

- Общая одногодичная выживаемость, \% пациентов

- Снижение уровня фоссоора в сыворотке крови на конец первого года терапии в ммоль/л.

На рисунке 1 и 2 отображено соотношение данных показателей для различных схем терапии применительно к временному горизонту исследования, равному 1 года. Горизонт исследования в 1 год выбран по причине того, что именно он является наиболее приемлемым с точки зрения формирования бюджета системы здравоохранения в Российской Федерации.

Терапевтическая эфффективность севеламера гидрохлорида и севеламера карбоната была принята равной у обоих препаратов на основании следующих РКИ:

- S. Fan, C. Ross, S. Mitra et al. A randomized, crossover design study of sevelamer carbonate powder and sevelamer hydrochloride tablets in chronic kidney disease patients on haemodialysis Nephrol Dial Transplant, 24 (2009), pp. 3794-3799 [13]

- J. Delmez, G. Block, J. Robertson, et al. A randomized, double-blind, crossover design study of sevelamer hydrochloride and sevelamer carbonate in patients on hemodialysis [14]

-S. Fishbane, J. Delmez, W.N. Suki, et al.A randomized, parallel, openlabel study to compare once-daily sevelamer carbonate powder dosing with thrice-daily sevelamer hydrochloride tablet dosing in CKD patients on hemodialysis [15]

Согласно исследованию Floege J [10]. выживаемость на конец первого года терапии на Вельсоро®500 и на севеламера карбонате была равной и составляла 88\%. Согласно описанным выше данным выживаемость на севеламера гидрохлориде также составляла 88\%.

По данным мета-анализа Jamal S.A., [11] при систематизированном 


\section{Общая одногодичная выживаемость,\%}

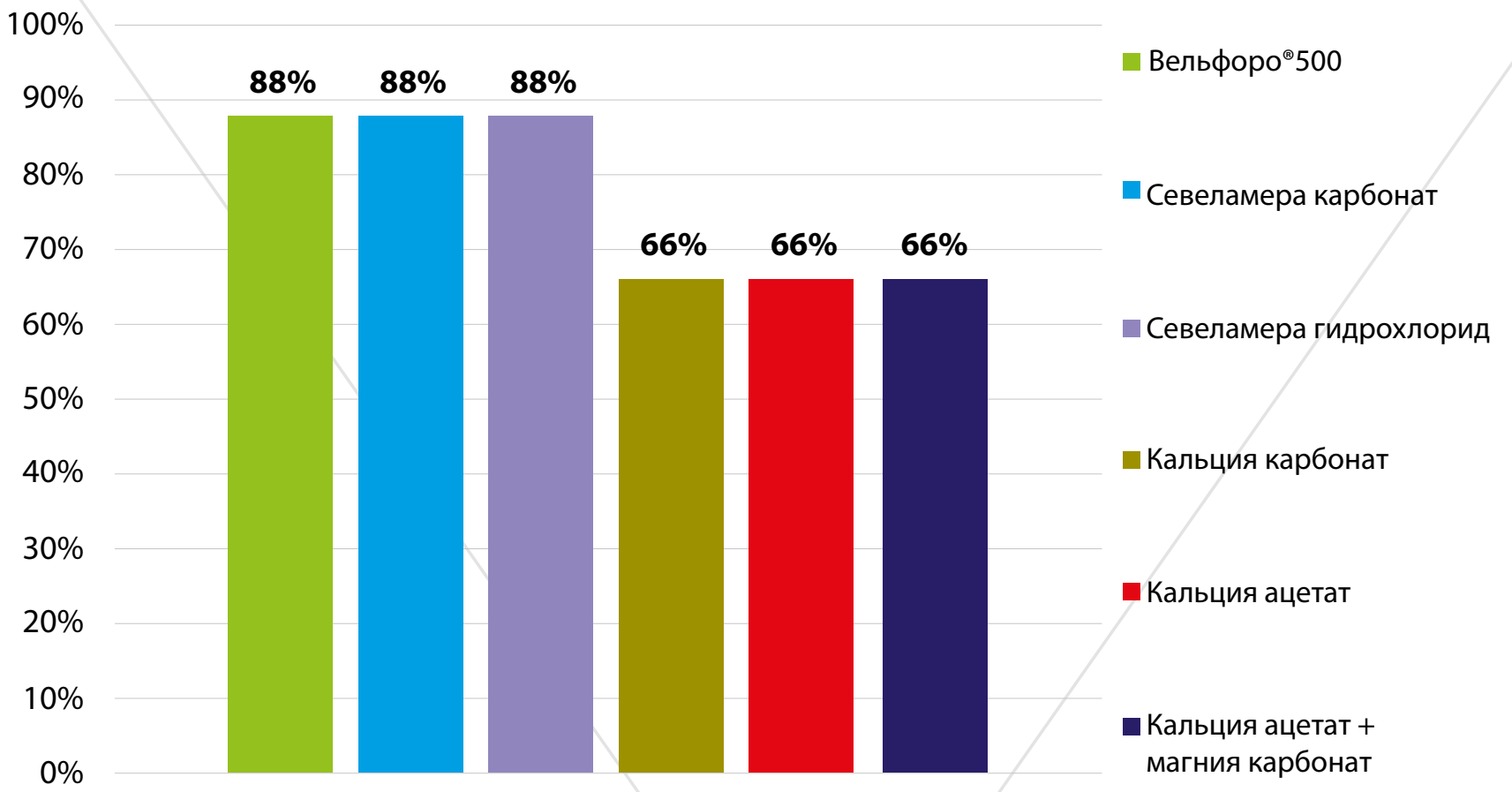

обзоре 11 ( $\mathrm{n=4622;} 936$ случаев смерти) у пациентов, получавших не содержащие кальций ФСП было выявлено снижение общей смертности на $22 \%$ по сравнению с таковой у пациентов, принимавших препараты Сa (относительный риск 0,78; 95\% ДИ 0,61-0,98). Следовательно, общая выживаемость для всех кальцийсодержащих ФСП в исследовании была принята за $66 \%$.

Снижение уровня сывороточного фоссрора на 52 неделе по данным Floege J [10] при терапии Вельсроро®500 составило 0,71 ммоль/л, применение севеламера карбоната привело к снижению уровня сывороточного фосфрора на 0,66 ммоль/л. Согласно описанным выше данным уровень снижения сывороточного фоссора на севеламера гидрохлориде также составил 0,66 ммоль/л. Уровень снижения для кальция ацетата+магния карбонат был взят из приведенной выше статьи Angel L.M. de Fransisco [12] и равнялся 0,55 ммоль/л. Для кальция ацетата и кальция карбоната данные значения были взяты из досье FDA для препарата Ренвела®, в котором было включено неопубликованное сравнительное исследование севеламера гидрохлорида и солей кальция. По его результатам снижение в группе солей кальция составило 0,58 ммоль/л.

Общее число больных в данном исследовании определялось по данным Российского регистра заместительной почечной терапии. Абсолютное число больных с хронической почечной недостаточностью,

\section{Снижение уровня фосфора в сыворотке крови на конец 1 года терапии (ммоль/л)}

Вельфоро ${ }^{\circledR} 500$

\section{0,71}

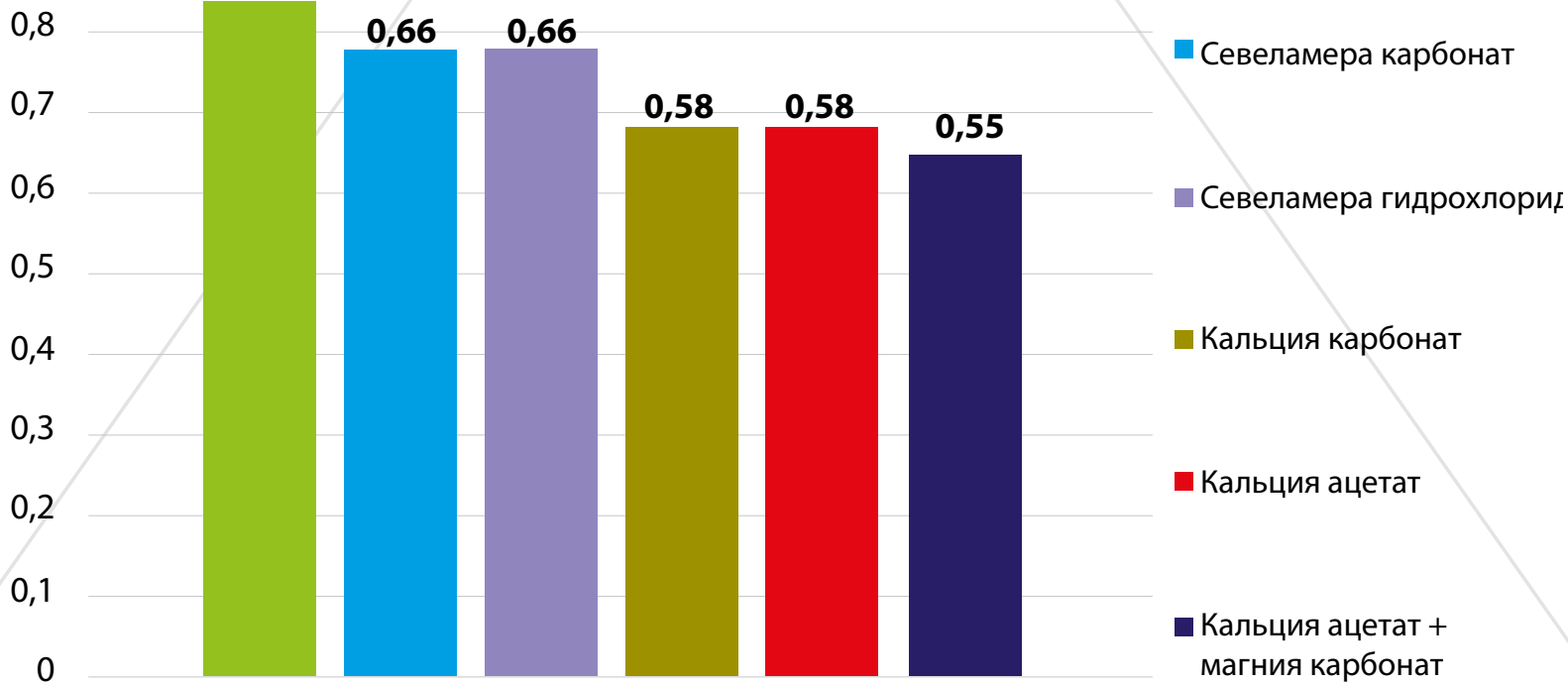

Рисунок 2. Снижение уровня сывороточного фосфора на конец первого года терапии (ммоль/л) 
получающих разные виды заместительной терапии равняется 28 840. В Российской Федерации в общей структуре диализной терапии преобладает гемодиализ (26 342 пациента) удельный вес которого находится на уровне 92,6\%. В то время как перитонеальный диализ получают 2098 человек (доля ПД составляет 7,4\%) [6]. По данным исследования Практики и исходов применения диализа (Dialysis Outcomes and Practice Patterns Study) доля пациентов с гиперфосфатемией из общего числа больных на заместительной почечной терапии составляет 53,6\% [16].

\section{Анализ затрат}

В ходе проведения настоящего исследования были определены значения составляющих анализа затрат при применении Вельфоро®500 в сравнении с применением других препаратов для лечения гиперфосфатемии.

Итоговое значение анализа затрат складывалось из:

- затрат на лекарственную терапию гиперфоссратемии

- затрат на лечение сердечно-сосудистых осложнений хронической болезни почек

- затрат на лекарственную терапию анемии и вторичного гиперпаратиреоза при хронической болезни почек

- затрат на лечение хронической болезни почек

Затраты на купирование прямых побочных явлений, вызванных приёмом ФСП, отдельно не оценивали, поскольку такие реакции этих препаратов отнесены к лёгким по степени тяжести.

В качестве источника информации о ценах на препараты для лечения гиперфосфатемии использовались данные Государственного реестра предельных отпускных цен производителей на лекарственные препараты, включенные в перечень жизненно необходимых и важнейших лекарственных препаратов согласно Распоряжению Правительства Российской Федерации от 26.12.2015 № 2724-р. Цены были учтены на момент 09.03.2016) Были взяты предельно допустимые оптовые цены без НДС (руб.) [17] с учетом оптовой надбавки для каждого региона Российской Федерации [18]. Рекомендуемая предельная отпускная цена производителя для препарата Вельфоро®500, равная 12500 руб, была рассчитана с помощью фармакоэкономической модели. Дозировки препаратов были взяты из инструкций по применению ЛС с учетом дозировок [28-30], использованных в клинических исследованиях анализа эффективности.
Следовательно, для препаратов севеламера суточная доза составила 7200 мг, для Вельфоро®500 - 1500 мг. Для кальция ацетата и кальция карбоната суточная доза составила 5000 мг (10 таблеток), для кальция ацетата + магния карбоната - 4350 мг (10 таблеток). Результаты расчётов затрат на 1 год лечения ФСП представлены в таблице 1. Было сделано допущение использовать оптовую ставку на лекарственные препараты в $10 \%$ согласно данным для г.Москвы. Однако фармакоэкономическая модель позволяет изменять значения оптовой ставки в соответствии с региональными нормативными актами того региона, в котором проводится исследование.

Затраты на лечение сердечно-сосудистых осложнений хронической болезни почек были рассчитаны в фармакоэкономическом исследовании Колбин А.С. , Курылев А.А. , Котенко О.Н., Волгина Г.В. Анализ медицинской технологии коррекции гиперфоссратемии при хронической болезни почек [19]. В данной работе были сопоставлены затраты на терапию препаратами севеламера и солями кальция, в результате авторы показали, что затраты на терапию сердечно-сосудистых осложнений ХБП с учетом частоты возникновения в группе севеламера составят 60287 руб., в группе препаратов солей кальция 172890 руб. В настоящем исследовании авторы делают допущение, что в группе не содержащих кальций ФСП (препараты севеламера и Вельфроро®500) значения данного вида затрат будут одинаковыми.

Затраты на лекарственную терапию анемии и вторичного гиперпаратиреоза при хронической болезни почек были рассчитаны следующим образом. В качестве источника инсрормации о ценах на препараты для лечения анемии и вторичного гиперпаратиреоза (ВГПТ) были использованы данные Государственного реестра предельных отпускных цен производителей на лекарственные препараты, включенные в перечень жизненно необходимых и важнейших лекарственных препаратов (по состоянию на 09.03.2016) Были взяты предельно допустимые оптовые цены без НДС (руб.) с учетом оптовой надбавки в $10 \%$ для г.Москвы. Однако в фармакоэкономической модели значения оптовой ставки были приведены в соответствии с региональными нормативными актами. Частота применения препаратов для лечения анемии и вторичного гиперпаратиреоза (ВГПТ) была взята из исследования Sprague SM, et al. [20] Результаты данной работы приведены в таблицах 2 и 3.

Таблица 1. Расчет затрат на лекарственную терапию гиперфоссратемии на 1 пациента за 1 год.

\begin{tabular}{|c|c|c|c|c|c|c|c|c|c|}
\hline Препарат & Дозировка & $\begin{array}{c}\text { Предельная отпуск- } \\
\text { ная цена произво- } \\
\text { дителя по данным } \\
\text { Государственного } \\
\text { реестра предельных } \\
\text { отпускных цен, руб.* }^{*}\end{array}$ & $\begin{array}{l}\text { Оптовая } \\
\text { ставка,\% }\end{array}$ & $\begin{array}{c}\text { Предельно } \\
\text { допустимая } \\
\text { оптовая цена } \\
\text { без НДС }\end{array}$ & $\begin{array}{c}\text { Суточная } \\
\text { доза в } \\
\text { мг }\end{array}$ & $\begin{array}{c}\text { Суточная } \\
\text { доза в } \\
\text { таблетках }\end{array}$ & $\begin{array}{c}\text { Цена } \\
1 \text { таблетки, } \\
\text { руб. }\end{array}$ & $\begin{array}{c}\text { Цена } \\
\text { суточной } \\
\text { дозы,руб. }\end{array}$ & $\begin{array}{c}\text { Затраты за } \\
1 \text { год, руб. }\end{array}$ \\
\hline Вельфоро ${ }^{\circledR} 500$ & $\begin{array}{c}500 \text { мг, } \\
90 \text { шт }\end{array}$ & $12500^{* *}$ & \multirow{3}{*}{$10,00 \%$} & 13750 & 1500 мг & 3 & 152,78 & 458,33 & 167292 \\
\hline $\begin{array}{c}\text { Севеламер } \\
\text { карбонат } \\
\left(\text { Селамерекс }{ }^{\circledR}\right)\end{array}$ & $\begin{array}{l}800 \text { мг, } \\
180 \text { шт }\end{array}$ & 9380 & & 10318 & 7200 мг & 9 & 57,32 & 515,90 & 188304 \\
\hline $\begin{array}{c}\text { Севеламер } \\
\text { гидрохлорид } \\
\left(\text { Ренагель }{ }^{\circledast}\right)\end{array}$ & $\begin{array}{l}800 \text { мг, } \\
180 \text { шт }\end{array}$ & 9381 & & 10319 & 7200 мг & 9 & 57,33 & 515,96 & 188324 \\
\hline $\begin{array}{c}\text { Кальция } \\
\text { карбонат } \\
\text { (Аддитива } \\
\text { кальций)*** }\end{array}$ & $\begin{array}{l}500 \text { мг } \\
\text { №10, }\end{array}$ & 256 & \multirow{3}{*}{$\begin{array}{c}\text { средняя } \\
\text { оптовая } \\
\text { цена без } \\
\text { НДС }\end{array}$} & 209,92 & 5000 мг & 10 & 20,99 & 209,92 & 76621 \\
\hline $\begin{array}{l}\text { Кальция ацетат } \\
\text { (Нефрродин)*** }\end{array}$ & $\begin{array}{l}475 \text { мг } \\
\text { №120 }\end{array}$ & 550 & & 451 & 5000 мг & 10 & 3,76 & 37,58 & 13718 \\
\hline $\begin{array}{c}\text { Кальция ацетат } \\
\text { + магния } \\
\text { карбонат } \\
\left(\text { (ОсваРен }^{\circledR}\right)\end{array}$ & $\begin{array}{l}435 \mathrm{Mr} \\
\text { №180 }\end{array}$ & 5473 & & 4926 & 4350 мг & 10 & 27,37 & 273,65 & 99882 \\
\hline
\end{tabular}

${ }^{*}$ на 09.03.2016

** рекомендуемая цена рассчитана с использованием фармакоэкономической модели

***биологически активная добавка 
Таблица 2. Распределение пациентов, получающих препараты эритропоэтинов на Вельфоро ${ }^{\circledR 500 ~ и ~ п р е п а р а т а х ~ с е в е л а м е р а . ~}$

\begin{tabular}{|c|c|c|}
\hline \multicolumn{3}{|c|}{ \% пациентов, получающих эритропоэтицы } \\
\hline Временной горизонт & Вельфоро ${ }^{\circledR} 500$ & Севеламер \\
\hline Начало исследования - неделя 12 & $63,20 \%$ & $81,60 \%$ \\
\cline { 2 - 3 } Неделя 12 - Неделя 24 & $78,30 \%$ & $85,00 \%$ \\
\cline { 2 - 3 } Неделя 24 - Неделя 36 & $78,90 \%$ & $85,90 \%$ \\
\cline { 2 - 3 } Неделя 36 - Неделя 52 & $77,60 \%$ & $86,30 \%$ \\
\hline
\end{tabular}

Таблица 3. Распределение пациентов, получающих препараты трехвалентного железа на Вельфоро ${ }^{\circledR 00}$ и препаратах севеламера.

\begin{tabular}{|c|c|c|}
\hline \multicolumn{3}{|c|}{ \% пациентов, получающих парентеральные препараты } \\
трехвалентного железа \\
\hline Временной горизонт & Вельфоро ${ }^{\circledR 00}$ & Севеламер \\
\hline Начало исследования - неделя 12 & $66,50 \%$ & $68,30 \%$ \\
\cline { 2 - 3 } Неделя 12 - Неделя 24 & $61,20 \%$ & $65,60 \%$ \\
\cline { 2 - 3 } Неделя 24 - Неделя 36 & $56,80 \%$ & $60,80 \%$ \\
\cline { 2 - 3 } Неделя 36 - Неделя 52 & $54,50 \%$ & $63,00 \%$ \\
\hline
\end{tabular}

Также по данным исследования Roggeri et al. за счет улучшенной биодоступности препаратов активаторов витамин-D-рецепторов при терапии Вельсоро®500 по сравнению с препаратами севеламера доля пациентов, переходящих с пероральных на внутривенные активаторы витамин-D-рецепторов выше на терапии препаратами севеламера на $2 \%$ по сравнению с Вельфоро®500 (2\% и 0\% соответственно).

Источником данных по дозировкам препаратов эритропоэтина служили инструкции по применению данных препаратов, а также научные публикации, описывающие опыт применения этих ЛС. [32] Следовательно, в модели была учтена ситуация, когда в группе больных на гемодиализе эпоэтин применяют в дозе 40-50 ЕД/кг 3 раза в неделю (120-150 ЕД/кг/нед). Пациентам на диализе дарбэпоэтин назначался подкожно или внутривенно в стартовой дозе 0,45 мкг/кг 1 раз в неделю, после стабилизации Нb был возможен переход на введение один раз в две недели [22] Режим дозирования препаратов метоксиполиэтиленгликоля эпоэтин бета выбирали исходя из допущения того, что ранее пациенты получали другой стимулятор эритропоэза (препараты эпоэтина в дозировке 10500
ЕД/нед) и их можно перевести на терапию препаратом метоксиполиэтиленгликоля эпоэтин бета с режимом введения 1 раз в 2 нед п/к или в/в в дозировке 100 мкг/2 недели [23]. Частота применения данных препаратов была принята согласно проекту Стандарта специализированной медицинской помощи пациентам с хронической болезнью почек 5 стадии, получающим лечение гемодиализом [24].

При расчете цен на парентеральные препараты трехвалентного железа авторы пользовались Государственным реестром предельных отпускных цен производителей на лекарственные препараты, если препарат в данном реестре отсутствовал, то пользовались базой данных оптовых цен на лекарственные препараты российского фармацевтического портала www.pharmindex.ru. [25].

Затраты на лечение хронической болезни почек в данной работе включали: затраты на проведение заместительной почечной терапии (ЗПТ) и затраты на госпитализацию пациентов. Затраты на ЗПт были рассчитаны исходя из того, что пациенты на гемодиализе проходили процедуру 3 раза в неделю, а пациентам на диализе проводили в среднем 4 обмена ежедневно, то есть 28 обменов в неделю [26]. Стоимость проведения ЗПТ была рассчитана по данным ФОМС, что составляло 5705 руб. за 1 услугу гемодиализа и 4528 руб за 1 день обмена, включающий 4 процедуры [27]. Также были учтены данные исследования Suki W.N.,2008 [32] свидетельствующие о том, что применение не содержащих кальций ФСП приводит к снижению частоты и длительности госпитализаций на 1 пациента в год по сравнению с приемом кальциевых ФСП. Стоимость госпитализации была учтена по данным тарифов ФОМС и составила 1944 руб. Результаты затрат на госпитализацию приведены в таблице 4.

Таблица 4. Затраты на госпитализацию пациентов при терапии хронической болезни почек при приеме различных фоссрат-связывающих препаратов.

\begin{tabular}{|c|c|c|}
\hline Показатель & $\begin{array}{c}\text { Не содержащие } \\
\text { кальций ФСП }\end{array}$ & $\begin{array}{c}\text { Кальцийсодержащие } \\
\text { ФСП }\end{array}$ \\
\hline $\begin{array}{c}\text { Средняя частота } \\
\text { госпитализаций на 1 } \\
\text { пациента в год }\end{array}$ & 2,1 & 2,9 \\
\hline $\begin{array}{c}\text { Средняя длительность } \\
\text { госпитализаций (дней) }\end{array}$ & 16,8 & 21,8 \\
\hline $\begin{array}{c}\text { Стоимость 1 койко-дня } \\
\text { (руб.) }\end{array}$ & 1944 & 1944 \\
\hline Общие затраты на \\
госпитализацию
\end{tabular}

Результаты анализа затрат приведены в таблице 5.

Таблица 5. Результат анализа затрат при терапии гиперфоссратемии.

\begin{tabular}{|c|c|c|c|c|c|c|}
\hline & Вельфоро ${ }^{\circledR 00}$ & $\begin{array}{c}\text { Севеламера } \\
\text { карбонат }\end{array}$ & $\begin{array}{l}\text { Севеламера } \\
\text { гидрохлорид }\end{array}$ & $\begin{array}{l}\text { Кальция } \\
\text { карбонат }\end{array}$ & Кальция ацетат & $\begin{array}{c}\text { Кальция ацетат + } \\
\text { магния карбонат }\end{array}$ \\
\hline $\begin{array}{l}\text { Затраты на лекарственную } \\
\text { терапию гиперфосфратемии }\end{array}$ & 167292 & 188304 & 188324 & 76621 & 13718 & 99882 \\
\hline $\begin{array}{c}\text { Затраты на лечение } \\
\text { хронической болезни почек }\end{array}$ & 1014688 & 1014688 & 1014688 & 1069004 & 1069004 & 1069004 \\
\hline $\begin{array}{c}\text { Затраты на лечение } \\
\text { сердечно-сосудистых } \\
\text { осложнений хронической } \\
\text { болезни почек }\end{array}$ & 60287 & 60287 & 60287 & 172890 & 172890 & 172890 \\
\hline $\begin{array}{c}\text { Затраты на } \\
\text { лекарственную терапию } \\
\text { анемии и вторичного } \\
\text { гиперпаратиреоза }\end{array}$ & 221771 & 253205 & 253205 & 253205 & 253205 & 253205 \\
\hline Общие затраты & 1464037 & 1516483 & 1516504 & 1571719 & 1508816 & 1594981 \\
\hline
\end{tabular}


На основании полученных значений в рамках проведения анализа затрат было сделано заключение о том, что применение препарата Вельфоро®500 является наименее затратной схемой лечения в условиях здравоохранения Российской Федерации на период в 1 год.

\section{Анализ «затраты-эффективность»}

Анализ «затраты-эффрективность» (CEA - cost-effectiveness analysis) используется для оценки стоимости единицы эффективности, представляемой сравниваемыми технологиями здравоохранения. Таким образом, данный вид фармакоэкономического анализа позволяет провести сравнение изучаемых технологий не только на основе итоговых значений анализа затрат, но и с помощью расчета коэффициента «затраты-эффективность» [7].

Коэфффициент «затраты-эфффективность» в данном исследовании определялся по формуле:

\section{CER=Cost/Ef}

где CER - коэфффициент «затраты-эффективность»; Cost - общие затраты на терапию гиперфосфатемии ФСП, руб.; Ef - одногодичная общая выживаемость, лет или снижение уровня фосфора в сыворотке крови на конец 1 первого года терапии, ммоль/л. Данный вид фармакоэкономического анализа позволяет определить, насколько затраты на ту или иную изучаемую технологию соответствуют ее эффективности, а также на основе полученных результатов выбрать наиболее предпочтительную с точки зрения фрармакоэкономики альтернативу [4,32].

Как было отмечено выше, в качестве критерия эффективности была выбрана общая одногодичная выживаемость пациентов и снижение уровня фоссфора в сыворотке крови на конец 1 года терапии. Результаты проведенного анализа «затраты-эффективность» представлены в таблице 6 и 7.

Таблица 6. Результаты анализа «затраты-эффективность» при использовании критерия эффективности «Общая одногодичная выживаемость».

\begin{tabular}{|c|c|c|c|}
\hline лС & $\begin{array}{c}\text { Сумма } \\
\text { затрат,руб. }\end{array}$ & $\begin{array}{c}\text { Значения } \\
\text { критерия } \\
\text { зффективности, } \\
\%\end{array}$ & $\begin{array}{c}\text { Коэффициент } \\
\text { «затраты- } \\
\text { эффективность» на } \\
\text { 1 год терапии, руб. }\end{array}$ \\
\hline Вельфоро ${ }^{\circledR 500}$ & 1464037 & 88 & 1663679 \\
\hline $\begin{array}{c}\text { Севеламера } \\
\text { карбонат }\end{array}$ & 1516483 & 88 & 1723277 \\
\hline $\begin{array}{c}\text { Севеламера } \\
\text { гидрохлорид }\end{array}$ & 1516504 & 88 & 1723299 \\
\hline Кальция карбонат & 1571719 & 66 & 2381393 \\
\hline Кальция ацетат & 1508816 & 66 & 2286086 \\
\hline $\begin{array}{c}\text { Кальция ацетат + } \\
\text { магния карбонат }\end{array}$ & 1594981 & 66 & 2416638 \\
\hline
\end{tabular}

Таблица 7. Результаты анализа «затраты-эффективность» при использовании критерия эффективности «Снижение уровня фосфора в сыворотке крови на конец 1 года терапии».

\begin{tabular}{|c|c|c|c|}
\hline лС & $\begin{array}{c}\text { Сумма } \\
\text { затрат, } \\
\text { руб. }\end{array}$ & $\begin{array}{c}\text { 3начения критерия } \\
\text { эффективности, } \\
\text { ммоль/л. }\end{array}$ & $\begin{array}{c}\text { Коэффициент } \\
\text { «затраты- } \\
\text { эффективность» } \\
\text { на 1 год терапии, руб. }\end{array}$ \\
\hline Вельфоро ${ }^{\circledR 00}$ & 1464037 & 0,71 & 2062024 \\
\hline $\begin{array}{c}\text { Севеламера } \\
\text { карбонат }\end{array}$ & 1516483 & 0,66 & 2297702 \\
\hline $\begin{array}{c}\text { Севеламера } \\
\text { гидрохлорид }\end{array}$ & 1516504 & 0,66 & 2297733 \\
\hline Кальция карбонат & 1571719 & 0,58 & 2709861 \\
\hline Кальция ацетат & 1508816 & 0,58 & 2601408 \\
\hline $\begin{array}{c}\text { Кальция ацетат + } \\
\text { магния карбонат }\end{array}$ & 1594981 & 0,55 & 2899965 \\
\hline
\end{tabular}

\section{Анализ «влияния на бюджет»}

Использование анализа «влияния на бюджет» подразумевает оценку всех видов расходов, связанных с внедрением новой схемы лечения относительно всех видов расходов уже существующей схемы лечения. Расчет расходов производился с использованием формулы:

$$
B I A=\text { Cost }_{1}-\text { Cost }_{2} \text {, где }
$$

Cost $_{1}$ - общая стоимость первого метода лечения (руб.);

Cost - общая стоимость второго метода лечения (руб.);

BIA (Budget Impact Analysis) - результат анализа «влияния на бюджет» (руб.); [8]

Таблица 7. Результаты анализа «влияния на бюджет» на одного пациента в год

\begin{tabular}{|c|c|c|}
\hline \multicolumn{3}{|c|}{ Анализ влияния на бюджет (100\% на 100\%) при переходе с другого ФСП } \\
на Вельфоро ${ }^{\circ 00}$
\end{tabular}

В ходе проведения настоящего исследования были определень значения составляющих анализа «влияния на бюджет» при применении Вельфоро ${ }^{\circledR} 500$ в лечении гиперфосфатемии в сравнении с применением ФСП. Итоговое значение для каждой группы складывалось из затрат на лекарственную терапию гиперфосфатемии, затрат на лечение сердечно-сосудистых осложнений хронической болезни почек, затрат на лекарственную терапию анемии и вторичного гиперпаратиреоза при хронической болезни почек, затрат на лечение хронической болезни почек.

Был проведен анализ «влияния на бюджет» с точки зрения системы здравоохранения для лечения гиперфосфатемии по двум сценариям текущая ситуация (Сценарий-1) и моделируемая ситуация (Сценарий-2) схем лечения. Данные сценарии предусматривают возможность регулировать долю пациентов с той или иной схемой терапии, а также в модели задать число больных. Временной горизонт анализа «влияния на бюджет» составил один год.

Таблица 8. Результаты анализа «влияния на бюджет» на одного пациента в год

\begin{tabular}{|c|c|c|c|}
\hline Сценарии & Схема терапии & $\begin{array}{c}\text { Доля } \\
\text { пациентов (\%) }\end{array}$ & $\begin{array}{c}\text { Затраты, } \\
\text { руб. }\end{array}$ \\
\hline \multirow{6}{*}{$\begin{array}{c}\text { Текущее } \\
\text { распределение }\end{array}$} & Вельфоро ${ }^{\circledR} 500$ & 0 & \multirow{6}{*}{1515548} \\
\hline & Севеламера гидрохлорид & 10 & \\
\hline & Севеламера карбонат & 15 & \\
\hline & Кальция карбонат & 25 & \\
\hline & Кальция ацетат & 25 & \\
\hline & $\begin{array}{c}\text { Кальция ацетат + магния } \\
\text { карбонат }\end{array}$ & 25 & \\
\hline \multirow{6}{*}{$\begin{array}{l}\text { Моделируемое } \\
\text { распределение }\end{array}$} & Вельфоро ${ }^{\circledR} 500$ & 45 & \multirow{6}{*}{1548002} \\
\hline & Севеламера гидрохлорид & 5 & \\
\hline & Севеламера карбонат & 5 & \\
\hline & Кальция карбонат & 15 & \\
\hline & Кальция ацетат & 15 & \\
\hline & $\begin{array}{c}\text { Кальция ацетат + магния } \\
\text { карбонат }\end{array}$ & 15 & \\
\hline \multicolumn{3}{|c|}{ Экономия денежных средств } & 36208 \\
\hline
\end{tabular}




\section{Анализ чувствительности}

В рамках данного фармакоэкономического исследования был проведен анализ чувствительности с целью определить степень устойчивости полученных результатов при изменении исходных параметров. В качестве изменяемого показателя были выбраны цены на все рассматриваемые ФСП. Односракторный анализ чувствительности проводили, оценивая изменения исходных параметров цены на исследуемые препараты при изменении параметров на величину от -50\% до 100\%. В ходе анализа чувствительности определили, что при изменении цены на Вельфоро® 500 на $100 \%$ результаты анализа «затраты - эфрфективность» остались устойчивы. Анализ чувствительности продемонстрировал стабильность данных, полученных в ходе фрармакоэкономического анализа.

\section{Выводы:}

В ходе фармакоэкономического анализа лечения гиперфоссратемии у пациентов с хронической болезнью почек на гемодиализе и перитонеальном диализе были получены следующие результаты:

1. Анализ «влияния на бюджет» показал, что терапия препаратом Вельфоро ${ }^{\circledR} 500$ является наименее затратной схемой лечения гиперфосфатемии у больных с хронической болезнью почек в Российской Федерации.

2. C позиции анализа «затраты-эфффективность» терапия препаратом Вельфоро ${ }^{\circledR} 500$ является доминантной технологией лечения гиперфоссратемии у больных с хронической болезнью почек по сравнению с другими фоссрат-связывающими препаратами.

3. Разработанная фрармакоэкономическая модель терапии гиперфоссратемии у больных с хронической болезнью почек в условиях здравоохранения Российской Федерации показала фармакоэкономическую эффрективность использования препарата Вельфоро ${ }^{\circledR} 500$ по сравнению со сравниваемыми препаратами

\section{Список литературы:}

1. В.М Ермоленко, Г.В.Волгина, В.А. Добронравов, Л.Я.Рожинская, А.В. Смирнов, Н.А.Томилина, Г.Д. Шостка. Национальные рекомендации по минеральным и костным нарушениям при хронической болезни почек. Нефрология и диализ. Т. 13, № 12011.

2. Г.В.Волгина, В. Штандель, О. Балкарова, Е. Ловчинский. Гиперфоссратемия при хронической болезни почек: современная стратегия коррекции. Врач. №3. 2012.

3. Е.М. Шилов. Коррекция гиперсросфатемии при хронической почечной недостаточности: роль севеламера. Клиническая несрология. №4. 2012

4. Хабриев Р.У., Куликов А.Ю., Аринина Е.Е. Методологические основы фармакоэкономического анализа. М.: Медицина, 2011. 128 с

5. Ягудина Р.И., Бабий В.В. Методологические основы анализа эффективности медицинских технологий при проведении фрармакоэкономических исследований // Фармакоэкономика: теория и практика. - 2015. - Т.3, №1. - C.7-11

6. Бикбов Б. Т., Томилина Н. А. Заместительная терапия больных с хронической почечной недостаточностью в Российской Федерации в 19982011 гг. (Отчет по данным Российского регистра заместительной почечной терапии. Часть первая) //Нефрология и диализ. М. - 2014. - С $11-127$

7. Ягудина Р.И., Серпик В.Г., Сороковиков И.В. Методологические основы анализа «затраты-эффрективность» // Фармакоэкономика: теория и практика. - 2014. - Т.2, №2. - С.23-26

8. Ягудина Р.И., Серпик В.Г., Угрехелидзе Д.Т. Методологические основы анализа «влияния на бюджет» // Фармакоэкономика: теория и практика. - 2015. - T.3, №4. - C.5-8

9. Floege J, Covic AC, Ketteler M, Rastogi A, Chong EM, Gaillard S, et al. A phase III study of the efficacy and safety of a novel iron-based phosphate binder in dialysis patients.

10. Floege J, Covic AC, Ketteler M, Mann JFE, Rastogi A, Spinowitz B, et al. Long-term effects of iron-based phosphate binder,sucroferric oxyhydroxide, in dialysis patients.

11. Jamal S.A., Ben Vandermeer, Raggi P. et al. Effect of calcium-based versus non-calcium-based phosphate binders on mortality in patients with chronic kidney disease: an updated systematic review and meta-analysis.
12. Ángel L.M. de Francisco, Lara Belmar, Celestino Piñera,et al. One year follow up effect of calcium acetate/magnesium carbonate in the treatment of hyperphosphataemia in dialysis patients in real clinical practice. Nefrologia 2014;34(5):617-27

13. S. Fan; C. Ross; S. Mitra; P. Kalra; J. Heaton; J. Hunter; M. Plone; N. Pritchard A randomized, crossover design study of sevelamer carbonate powder and sevelamer hydrochloride tablets in chronic kidney disease patients on haemodialysis Nephrol Dial Transplant, 24 (2009), pp. 3794-3799

14. Delmez J, Block G, Robertson J, Chasan-Taber S, Blair A, Dillon M, et al. A randomized, double-blind, crossover design study of sevelamer hydrochloride and sevelamer carbonate in patients on hemodialysis. Clin Nephrol. 2007;68(6):386-391S.

15. Fishbane, J. Delmez, W.N. Suki, et al.A randomized, parallel, open-label study to compare once-daily sevelamer carbonate powder dosing with thrice-daily sevelamer hydrochloride tablet dosing in CKD patients on hemodialysis. American Journal of Kidney Diseases, Volume 55 , Issue $2,307-315$

16. Dialysis Outcomes and Practice Patterns Study http://www.dopps.org/ (Дата обращения: 29.02.2016)

17. Государственный реестр предельных отпускных цен http://grls. rosminzdrav.ru/pricelims.aspx (Дата обращения: 09.03.2016)

18. Калькулятор надбавок ЖНВЛП http://www.pharmvestnik.ru/calcs/drugs/ (Дата обращения: 29.02.2016)

19. Колбин А.С. , Курылев А.А., Котенко О.Н. , Волгина Г.В. Анализ медицинской технологии коррекции гиперфоссратемии при хронической болезни почек. Качественная клиническая практика.№3 2013.

20. Sprague SM, et al. Post hoc analysis of antianemic agent use over 1 year in a phase 3 study of sucroferric oxyhydroxide. Abstract of poster presented at the National Kidney Foundation Spring Clinical Meetings, March 2015, Dallas, Texas

21. Ю. С. Милованов, Л. В. Козловская, А. Ю. Николаев, В. В. Фомин, Л. Ю. Милованова. Анемия у больных с хронической почечной недостаточностью: принципы терапии. Лечащий врач выпуск \#07/05

22. Шило В. Ю. Новый эритропоэз-стимулирующий препарат Аранесп (дарбэпоэтин альфа) в коррекции анемии почечного генеза. Журнал «Нефрология и диализ» Т. 9, 2007 г., №3

23. Инструкция по применению препарата Мирцера. Государственный реестр лекарственных средств. http://grls.rosminzdrav.ru/grls.aspx

24. Проект Стандарта специализированной медицинской помощи пациентам с хронической болезнью почек 5 стадии, получающим лечение гемодиализом https://www.rosminzdrav.ru/documents/8036-standartspetsializirovannoy-meditsinskoy-pomoschi-patsientam-s-hronicheskoyboleznyu-pochek-5-stadii-poluchayuschim-lechenie-gemodializom-proekt

25. База данных оптовых цен на лекарственные препараты www. pharmindex.ru (Дата обращения: 09.03.2016)

26. Абдрашитова Г.Т., Ягудина Р.И., Серпик В.Г. Фармакоэкономический анализ оказания медицинской помощи больным с хронической болезнью почек, нуждающимся в проведении заместительной почечной терапии методами перитонеального диализа и гемодиализа в условиях Российского здравоохранения // Фармакоэкономика: теория и практика. - 2015. - Т.3, №3. - С.103-110

27. Тарифы Фонда обязательного медицинского страхования http://www. ffoms.ru/

28. Инструкция по применению препарата Вельфоро ${ }^{\circledR 500}$. Государственный реестр лекарственных средств. http://grls.rosminzdrav.ru/grls.aspx

29. Инструкция по применению препарата Ренагель ${ }^{\circledR}$. Государственный реестр лекарственных средств. http://grls.rosminzdrav.ru/grls.aspx

30. Инструкция по применению препарата Селамерекс ${ }^{\circledR}$. Государственный реестр лекарственных средств. http://grls.rosminzdrav.ru/grls.aspx

31. Suki W.N., Zabaneh R., Cangiano J.L. et al. Effects of sevelamer and calcium-based phosphate binders on mortality in hemodialysis patients. // Kidney Int. 2007; 72 (9):1130-1137

32. Ягудина Р.И., Куликов А.Ю., Угрехелидзе Д.Т. Определение порога «готовности платить» при одобрении медицинских технологий в условиях российского здравоохранения, рассчитанного на основе паритета покупательной способности // Фармакоэкономика: теория и практика.

- 2015. - T.3, №3. - C.5-9 